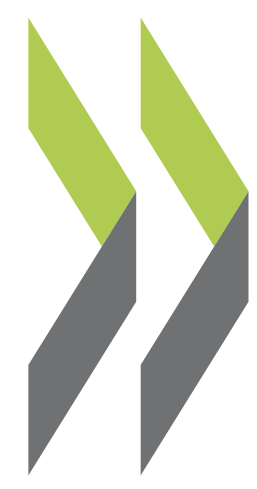

OECD Economics Department Working Papers No. 13

\title{
The Demand for Money and Velocity in Major OECD Countries
}

Adrian Blundell-Wignall,

M. Rondoni, 


\section{OECD \\ ECONOMICS AND STATISTICS \\ DEPARTMENT}

\section{WORKING PAPERS}

No.13: THE DEMAND FOR MONEY AND VELOCITY IN MAJOR OECD COUNTRIES

by

A. Blundell-Wigna11

M. Rondoni

H. Ziegelschmidt

Monetary and Fiscal Policy Division

February 1984

(0)

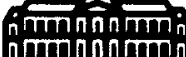

(DECD 

ECONOMICS AND STATISTICS DEPARTMENT

WORKING PAPERS

\begin{abstract}
This series of Working Papers is designed to make available, to a wider readership, selected studies which the Department has prepared for use within the OECD. Authorship is generally collective, but main individual authors are named. The Papers are available both in English and French.

Comment on the Papers is invited, and may be sent to OECD, Department of Economics and Statistics, 2 rue André Pascal, 75775 Paris Cedex 16, France. Additional copies of the Papers on a limited basis can be forwarded on request.
\end{abstract}

ORGANISATION FOR ECONOMIC CO-OPERATION AND DEVELOPMENT

Copyright OECD, 1984

19813 

(i)

THE DEMAND FOR MONEY AND VELOCITY IN MAJOR OECD COUNTRIES

by

A. Blunde11-Wignal1

M. Rondoni

H. Ziegelschmidt*

* Respectively Principal Administrator, Consultant and Administrator, Monetary and Fiscal Policy Division. The views expressed reflect the opinions of the authors and do not necessarily represent those of the OECD or its Member governments. The authors are grateful for comments of other members of the OECD Secretariat.

2319E. 
I. INTRODUCTION

II. MONEY DEMAND EQUATIONS FOR THE MAJOR 7 OECD COUNTRIES 2

A. The standard money demand equation 2

B. Opportunity cost arguments of money demand 4

C. Results for the standard money demand equations with inflation expectations

D. Suppressing expected inflation 5

E. An overview of the results 6

III. THE ANALYSIS OF MONEY DEMAND STABILITY 7

A. The Chow test 7

B. Recursive regression tests $\quad 8$

C. Moving regression and time trend tests 8

D. Change points and financial innovations 9

(1) United States 9

(2) Japan $\quad 9$

(3) Germany $\quad 9$

(4) France 9

(5) United Kingdom $\quad 10$

(6) Italy 10

(7) Canada 10

E. An overview of the stability results 10

IV. PREFERRED EQUATIONS AND TEST OF THE LAG STRUCTURE $\quad 11$

V. DYNAMIC SIMULATIONS OF VELOCITY 14

VI. CONCLUDING REMARKS $\quad 17$

$\begin{array}{ll}\text { ANNEX } & 20\end{array}$ 


\section{INTRODUCTION}

In recent years the behaviour of the income velocity of money in major OECD economies has displayed considerable volatility for both narrow and broad monetary aggregates (Table 1). Velocity in a number of large OECD economies, for example, fell sharply in 1982. Most notably, declines in the income velocity of MI, M2 and M3 in the United States of 2.3, 4.9 and 5.9 per cent, respectively, were large by historical standards. Such movements in velocity may arise as a consequence of changes in money demand in two important ways:

i) they may result from movements along the money demand function, as the normal implication of changes in its interest rate and inflation expectations arguments; and

ii) the money demand function itself may shift (money demand instability), leading to unpredictable changes in velocity.

Velocity may also move as the mechanical result of policies by the authorities which alter the supply of money in the short run, while the private sector is able to adjust only with substantial lags.

The relative importance of (i) and (ii) in determining movements in velocity is an important issue, because it bears on the efficacy of monetary targeting. Provided that the demand for money function is stable, velocity too will be stable, in the sense of being predictable. In this case, monetary targets will tend automatically to stabilize the economy in the face of real economic shocks. For example, a rise in the budget deficit will put upward pressure on interest rates in order to affect a transfer of funds from private lenders to finance the deficit, causing velocity to rise. On the other hand, a monetary target will destabilize the economy in the face of shifts in the demand for money function. Thus, an upward shift of the function would reduce Iong-run velocity and, in the absence of monetary accommodation, will result in upward pressure on interest rates. The financial disturbance will result in a fall in the demand for goods, which could have been avoided by deviating from the monetary target to accommodate the increased demand for money balances (1). In the absence of destabilizing expectations, such a deviation from the monetary target would not be inflationary.

There has been a voluminous literature on the estimation of money demand equations (2). Traditionally, these studies have employed single equation estimation techniques. This runs the risk of encountering substantial estimation bias as a consequence of ignoring the simultaneity of the supply-side policies of the monetary authorities mentioned above. Nevertheless, most have managed to identify "reasonable" results for some aggregates over various sample periods during the 1970 s in most major OECD economies. However, parameter instability between sub-periods has also been an important finding. More recently, a spate of financial innovations, particularly in the United States, Japan, the United Kingdom and Canada, have led to the conjecture that money demand equations may have become less stable, and that the aggregates concerned may have become a less reliable guide for policy (3). In more general terms, if it could be demonstrated that demand for money functions were everywhere unstable, the case for monetary targeting would be somewhat weakened. 
The purpose of this paper is to re-estimate traditional money demand equations over sample periods which include recent data, to test their stability, and to examine whether they provide a reasonable explanation of large swings in velocity during the 1970 s and 1980s. To some extent this follows up previous work done within the OECD (see OECD (1979)): However, interesting features of the approach adopted here include:

-- All sample periods commence in the quarter during which the country concerned shifted to flexible exchange rates. This switch gave the authorities greater control over the money supply, and constituted an important structural change that may have led to instabilities in earlier studies.

-- Given the variability of inflation over the 1970 s and 1980 s, inflation expectations have been included as the predictions of a random walk and, alternatively, as forecasts from estimated autoregressive equations for inflation. These are compared to specifications that suppress the inflation term altogether.

-- The equations have been subjected to a more searching battery of stability tests than has normally been carried out in other'studies.

-- The traditionally assumed lag structure has been tested against a more general alternative.

Section II examines results for three alternative specifications of the demands for $M 2, M 2$ and $M 3$ in the major seven $O E C D$ economies. Results from tests of the stability of these equations are presented in Section III. In Section IV the Koyck lag structure is tested against a more general alternative. Section $V$ discusses results of dynamic simulations of velocity with selected money demand equations. Finally, some concluding remarks are made in Section VI.

\section{MONEY DEMAND EQUATIONS FOR THE MAJOR 7 OECD COUNTRIES}

A. The standard money demand equation

The standard specification used in the analysis of money demand is a first order (Koyck) partial adjustment towards long-run real money demand $(\mathrm{M} / \mathrm{P})^{\mathrm{D}}$ of the form:

$$
\begin{aligned}
& \operatorname{Dln}\left(\frac{\mathrm{M}}{\mathrm{p}}\right)=\propto\left[\ln \left(\frac{\mathrm{M}}{\mathrm{p}}\right)^{\mathrm{D}}-\ln \left(\frac{\mathrm{M}}{\mathrm{p}}\right)_{-1}\right] \\
& \ln \left(\frac{\mathrm{M}}{\mathrm{p}}\right)^{\mathrm{D}}=\ln \mathrm{k}+\mathrm{B}_{1} \ln \mathrm{y}+\mathrm{B}_{2} \ln (1+\mathrm{r})+\mathrm{B}_{3} D \operatorname{lnp} \mathrm{e}
\end{aligned}
$$

where $M$ is the money stock, $p$ is the price level, $r$ is a short-term interest rate, and $\mathrm{p}^{\mathrm{e}}$ is the expected price level (4). $\mathrm{D}=\mathrm{d} / \mathrm{dt}$, and expected signs are $0<\alpha \leqslant 1, B_{1}>0 ; B_{2}, B_{3}<0$. The simple Koyck lag used follows previous research, e.g. OECD (1979), but is also chosen to facilitate incorporation of the results into a wider modelling project within the OECD. 
Table 1

RECENT VELOCITY DEVELOPMENTS

(Annual percentage changes)

\begin{tabular}{|c|c|c|c|c|}
\hline & & M1 Velocity & M2 Velocity & M3 Velocity \\
\hline \multirow[t]{3}{*}{ United States } & 1980 & 2.5 & 0.8 & -0.2 \\
\hline & 1981 & 4.8 & 2.5 & 0.6 \\
\hline & 1982 & -2.3 & -4.9 & -5.9 \\
\hline \multirow[t]{3}{*}{ Japan (a) } & 1980 & 6.9 & -0.8 & n.a. \\
\hline & 1981 & 2.9 & -2.0 & n.a. \\
\hline & 1982 & 0.2 & -3.5 & n.a. \\
\hline \multirow[t]{3}{*}{ Germany } & 1980 & 4.1 & 1.2 & 2.4 \\
\hline & 1981 & 2.6 & -2.5 & 0.1 \\
\hline & 1982 & 0.0 & -2.8 & -1.4 \\
\hline \multirow[t]{3}{*}{ France } & 1980 & 4.2 & 1.2 & 1.2 \\
\hline & 1981 & -0.7 & -0.7 & -0.7 \\
\hline & 1982 & 0.1 & 1.7 & 1.7 \\
\hline \multirow[t]{3}{*}{ United Kingdom } & 1980 & 11.3 & n.a. & 1.0 \\
\hline & 1981 & -0.9 & n.a. & -7.4 \\
\hline & 1982 & 0.2 & n.a. & -2.6 \\
\hline \multirow[t]{3}{*}{ Italy } & 1980 & 8.2 & 9.7 & 5.1 \\
\hline & 1981 & 6.5 & 6.9 & 1.4 \\
\hline & 1982 & 5.1 & 4.6 & 0.9 \\
\hline \multirow[t]{3}{*}{ Canada (b) } & 1980 & 2.9 & 5.6 & -4.0 \\
\hline & 1981 & 7.6 & -0.8 & 1.0 \\
\hline & 1982 & -0.3 & -3.8 & 0.2 \\
\hline
\end{tabular}
a. $\quad M 2+C D$ for Japan.
b. MIA for Canada. 
In particular, it simplifies estimating equations on quarterly data and subsequently converting them to biannual equations necessary for incorporation into the OECD Financial Interlink model. However, the question of whether or not the restrictions implied by the Koyck lag structure are accepted by the data is tested for the preferred equation for each country in Section IV below.

\section{B. Opportunity cost arguments of money demand}

Economic agents may hold money balances instead of financial assets, in which case they forego the interest payable on those assets. A market interest rate is normally included as an opportunity cost argument of estimated money demand equations. However, in recent years financial innovations ( particularly in the United States and Canada) pose difficulties, in principle, for identifying stable opportunity cost arguments, even for narrow $\mathrm{Ml}$ aggregates. In particular, the introduction of chequing deposits that pay a return may alter the interest rate elasticity of money demand. This has always been a problem with estimating equations for $M 2$ and $M 3$ demand, which include various time deposits that pay interest. These difficulties are further increased when one considers the changes in the range of services offered by banks in most countries in recent years. These imply the possibility of shifts of the non-pecuniary return on holding various types of bank deposits. The correct opportunity cost argument for inclusion in money demand equations might be considered to be:

$$
(1+r)^{\prime}=\frac{1+r}{1+r_{1}+r_{2}}
$$

where $r_{1}$ is the pecuniary return on bank deposits, and $r_{2}$ is the non-pecuniary return (services, etc.). In light of the difficulties of measuring $r_{1}$ and $r_{2}$, however, it is assumed that $1+r_{1}+r_{2}$ may be approximated by a constant. Since the equations are estimated in logarithms, this term is assumed to be captured by the constant term in the money demand equation for each country.

Expected inflation, as the return on goods and services, is a1so typically included in estimated money demand functions as an opportunity cost argument. However, unlike the relatively stable returns on bank deposits in most countries, this term is known to have been highly variable in recent years and should, in principle, be included as a specific argument of empirical money demand equations. In OECD (1979) expectations are assumed to be static, so that the current inflation rate proxies the expected future inflation rate as in a random walk ( $R W$ ) equation.

$$
\text { DIn } \mathrm{p}^{\mathrm{e}}=\mathrm{D} \ln \mathrm{p}_{-1}+\epsilon
$$

These are referred to as "RW Price Expectations" in the money demand results reported below. However, in most of the major seven OECD economies inflation rate series are not, in general, random walks, implying the existence of information in the residuals of the random walk model which could improve agents forecasting of future inflation. Consequently, an alternative naive model of price expectations was formulated in terms of forecasts from autoregressive (AR) equations for the rate of inflation of the general form: 


$$
\begin{aligned}
D_{1 n p}{ }^{2}= & \text { CONST }+\psi_{1} \text { Dlnp }_{-1}+\psi_{2} \text { Dlnp }_{-2}+\psi_{3} \text { DInp }_{-3} \\
& +\psi_{4} \text { Dlnp }_{-4}+\psi_{5} \text { Dlnp }_{-5}+\epsilon
\end{aligned}
$$

The estimated results are shown in Table Al of the Annex. The one period forecasts from the estimated equations were used as an alternative to the random walk measure of expected inflation, and are referred to as "AR Price Expectations" in the money demand results reported below.

\section{Results for the standard money demand equations with inflation expectations}

Tables A2 and A3 of the Annex present OLS estimates for the standard money demand equation applied to $\mathrm{Ml}$, for both the RW and AR price expectations variables, respectively. The sample period covers floating exchange rates 1973.Q2 to 1983.Q1, except for the United Kingdom and Canada, both of whom began floating somewhat earlier. The equations with RW price expectations in all cases give rise to parameters with the expected a priori sign and, with the notable exception of the United States, plausible long-run elasticities for real income, interest rates and inflation. The near zero partial adjustment Koyck coefficient in the case of the United States gives rise to highly implausible results for that country. The real income elasticities are poorly determined in the cases of Japan and the United Kingdom. The Durbin h-statistic suggests the presence of autocorrelation in the residuals of the equation for MI demand in France.

With AR price expectations (Table A3) autocorrelation is present in the error terms of the M1 equations for both France and the United States. Considerably more plausible estimates of the lag coefficients, interest and inflation elasticities are obtained for the United States, France and the United Kingdom. In the case of the United Kingdom, however, the more plausible income elasticity is associated with an estimate for the inflation expectations term which is insignificantly different from zero.

Tables A4 and A5 of the Annex show estimates of the standard money demand equation for M2. Satisfactory equations were obtained only for the United States with RW and AR price expectations. For all other countries the parameters are insignificant, of an inappropriate sign, and/or give rise to implausible long-run elasticities. A similar picture emerges in the case of M3, shown in Tables A6 and A7. The equation is broadly acceptable for the United States with RW price expectations, but for all other countries the results are unsatisfactory. AR price expectations do not improve the M3 results in any important respect.

\section{Suppressing expected inflation}

In recent years inflation and short-term interest rates have had some tendency to move together, while inflation and output are of ten related inversely. Typically, inflation, once having been permitted to accelerate, has been countered at a relatively late stage by sharply rising interest rates. This, in turn, has had adverse consequences for real activity. Consequently, there are some grounds to anticipate collinearity problems in the estimation of real income and interest rate elasticities of money demand 
functions, if a variable which is close to the actual inflation rate is included. This is certainly true of the $R W$ and $A R$ forecasts used to proxy expected inflation in this study. Moreover, nominal interest rates may already include a substantial expected inflation premium, so that some "double counting" may also give rise to collinearity problems when both of these terms are included for estimation. Finally, the $R W$ and $A R$ approximations used may embody substantial measurement error in comparison to the "true" expected rate of inflation. Evidence for this may be seen in that there is no consistent selection of either series for different aggregates within the same country. For example, AR price expectations improve the $M 1$ results for the United States compared to RW price expectations, but the reverse is true for the M3 results. Consequently, the term was suppressed, and all equations were re-estimated over identical sample periods.

The $\mathrm{MI}$ results with the inflation term suppressed are shown in Table A8 of the Annex. In relation to the previous "best" results, long-run elasticities and t-statistics associated with the income term are more plausible in the cases of the United States, Japan and Canada. For the interest rate term, $t$-statistics substantially improve in the cases of the United States and France. The lag parameter generally suggests slightly more rapid adjustment to long-run equilibrium when the inflation term is suppressed. In the case of the United Kingdom, it was noted above that the AR price expectations parameter was insignificantly different from zero and that the results for the income term improved. Results with the inflation term suppressed are, therefore, similar to this earlier finding. Durbin h-statistics are broadly satisfactory with the exception of France.

The results for M2 (Table A9 of the Annex), show much more substantial differences in comparison to those with the inflation expectations term included. For the United States the long-run income and interest rate elasticities rise, but the possibility that these estimates are biased is underlined by the deterioration of the Durbin h-statistic. The estimates are also less plausible in the case of Canada. For Japan, France and Italy, the previous inappropriate signs and/or magnitudes of the parameters on the income term are "corrected" by suppressing the inflation term. In the case of Japan, however, the Durbin h-statistic also rises markedly, possibly implying an inappropriate dynamic structure and/or a missing variables problem. The M3 results (Table AlO of the Annex) improve for Germany and France, but deteriorate substantially for the United States. For other countries the M3 results are unsatisfactory, whether or not an inflation term is included.

\section{E. An overview of the results}

Table 2 summarizes the main findings of the detailed results shown in Tables A2 to A10 of the Annex. It is of some interest that a reasonable M1 equation can be obtained for all of the major OECD economies, with the exception of France. Plausible estimates can also be obtained for M2 the United States, France and Italy. For M3 reasonable estimates were obtained only for the United States, Germany and France. In general, the results tend to deteriorate as the broadness of the aggregate is increased. One possible explanation for this is that the narrower M1 concept is much more likely to be "demand-determined" at all points in time. Portfolio holders can switch relatively easily between transactions and time deposits in order to remain on their short-run narrow money demand functions in response to changes in 
Table 2

OVERVIEW OF ESTIMATION RESULTS

$A=$ Equation with $R W$ price expectations preferred

$B=$ Equation with AR price expectation preferred

$\mathrm{C}=$ Equation with inflation term suppressed preferred

- = No plausible result obtained

\begin{tabular}{llll}
\hline & M1 & M2 & M3 \\
United States & B, C & A, B & A \\
Japan & C & - & n.a. \\
Germany & A,C & - & C \\
France & - & C & C \\
United Kingdom & C & n.a. & - \\
Italy & A,B,C & C & - \\
Canada & A,B,C & - & - \\
\hline
\end{tabular}

interest rates, etc. In the case of broader aggregates - particularly M3, which in some countries (France, Italy) includes short-run treasury bills portfolio substitution requires switches into substantially more illiquid assets. In these circumstances, policies of the monetary authorities which impact on overall bank credit expansion may have direct effects on $M 2$ and/or M3. In these circumstances there may be important simultaneity problems in estimation between demand and supply factors which adversely affect the estimation of an equation for the broader aggregates.

III. THE ANALYSIS OF MONEY DEMAND STABILITY

\section{A. The Chow test}

The question of whether the presented money demand functions are stable, i.e. the issue of constancy of the estimated coefficients over time, has been examined with several statistical tests. In a first approach the equations have been subject to a Chow test with the sub-intervals from the start date to the third quarter of 1979, and from the fourth quarter of 1979 to the first quarter of 1983 for all countries, monetary aggregates and specifications (5). The test statistics and critical values at a 5 per cent and 1 per cent level of significance are reported in Table All of the Annex. A majority of the above demand for money equations pass this standard stability test. All aggregates and specifications are consistent with stability in the cases of Japan, Germany and the United Kingdom. For the United States, the hypothesis of stability is rejected only for the M2 and M3 specifications without the inflation expectations term. Conversely, equations for the broad aggregates excluding the inflation terms are consistent with stability for France. In the case of Italy, all M3 equations and the M1 function without the inflation term pass the Chow test. For Canada, all specifications for M1A pass, and all M2 and M3 equations fail. 


\section{B. Recursive regression tests}

This preliminary stability check, however, suffers from the arbitrariness of the split of the complete estimation period into two sub-intervals. Consequently, recursive regressions (6) were run to test for changes in parameters that cannot be explained by random movements around a time-invariant true parameter value. The cusum test examines whether the normalised cumulative sums of recursive regression residuals significantly differ from zero. The hypothesis of stability of an equation is rejected at a 1 and 5 per cent levels of significance if the test statistic is greater than its critical values of 1.143 and 0.948 , respectively (indicated by asterisks in Table A11). Consistent with the preliminary Chow test, the equations perform surprisingly well. All aggregates and equations pass the cusum test in the United States and France. Only one out of nine equations fails for Germany, all MI specifications pass the test for Japan, the United Kingdom and Italy, while for Canada all specifications for $M 1$ and $M 3$ are satisfactory. Comprehensive rejections of stability with the cusum test may be observed for M2 in Japan and Canada, and for ster1ing M3.

The supplementary cusum of squares test relates the cumulative sums of squared recursive residuals to its total sum, and examines whether these ratios significantly differ from its beta-distributed expected values. Its critical values depend on the degrees of freedom, and are shown in Table All for the 1 and 5 per cent level of significance. The results for this test give rise to considerably more rejections of the null hypothesis of parameter stability (7). None of the United States' money demand functions pass the test, all M2 equations fail for Japan and Germany, and all M3 specifications are rejected for the United Kingdom, Italy and Canada. With the exception of the United States, however, there exists for all the other countries at least one specification of a money demand function which passes not only the cusum of squares test, but all the stability checks discussed so far. In this context, the stability of all specifications for $M 1$ in Japan, the United Kingdom and Canada, and for M3 in Germany, is impressive.

\section{Moving regression and time trend tests}

To further scrutinize the behaviour of regression coefficients over time, two more stability tests have been carried out. The "homogeneity statistic" is calculated by running regressions over successive intervals of a given length (moving regressions), using a variant of the analysis of variance test for non-overlapping groups. The $f$-distributed test statistic and critical values at a 1 per cent significance level are given in Table All. The equations were also tested to see whether significantly better fits than those presented in Tables A2 to A10 could be obtained if the regression coefficients were assumed to be polynomials in time. The technique requires the calculation of the sum of squares removed by each of a set of nested hypotheses. The test statistic is again $F$ distributed, and is also presented in Table All, along with its critical value at the 1 per cent level. For simplicity, the polynomials were restricted to degree 1, i.e. the regression coefficients were allowed to become linear functions of time.

The results of these two alternative tests largely corroborate previous findings. These tests rejected the null hypothesis of parameter stability only where it had already been rejected by the Chow or the two cusum tests. 
On the other hand, it is interesting to note that money demand equations for the United States which failed the cusum of squares test, passed in seven out of nine specifications both the homogeneity test and the time-trending regression test.

\section{Change points and financial innovations}

In order to identify periods where the change of parameters over time is concentrated, for all of the above money demand specifications, Quandt's $10 g-1$ ikelihood ratio was computed (8). This ratio is likely to be at a minimum at a true change point, and these periods are also shown in Table All of the Annex.

1. United States. Low points of the ratio for the M1 equations are mainly observed in late 1979, reaching a minimum in the first quarter of 1980. This suggests that the switch to the new operating procedure by the Federal Reserve in October 1979 is more likely to have contributed to instability than subsequent financial innovations. A Chow test suggests that this break point is significant if AR price expectations are ignored, but not if they are included. For M2 and M3 there is some evidence of breaks at later points in 1980 and 1981. These periods are associated with the removal of ceilings on interest rates payable by banks, which led to the re-intermediation of large classes of non-bank liabilities that serve as quasi money (e.g. money market mutual funds). However, while these change points are significant for all specifications of the $M 3$ equation, this is not the case for $M 2$ with $A R$ price expectations. In sum, the $M 1$ and $M 2$ specifications with AR price expectations seem reasonably stable, but financial innovation may have significantly altered the demand for $M 3$.

2. Japan. Low points of the Quandt ratio for both $M 1$ and $M 2+C D$ are concentrated in the mid-1970s, rather than in the more recent periods of financial innovations (e.g. the availability of 1iquid deposit instruments with securities companies that can be withdrawn at short notice, and the evolution of ordinary deposit accounts (futsu yokin) into general accounts (sego hoza) with overdraft facilities). This corresponds to the period when greater emphasis was placed on controlling $\mathrm{M} 2$, as opposed to interest rate targeting, mainly through a strengthening of quantitative restrictions on bank lending. M2 growth of around 27 per cent at the end of 1972 was reduced to 10 per cent by the end of 1974, and has subsequently remained under firm control. It is interesting to note that Chow tests at these break points are significant for $M 2+C D$, but not for $M 1$.

3. Germany. Significant break points are found for M1 and M2 around the mid-1970s, which corresponds approximately with the choice of central bank money as an intermediate target. For M3, however, none of these change points are associated with a significant Chow statistic.

4. France. Change points are mostly concentrated in the mid 1970 s for al1 aggregates. Chow tests suggest that these are significant for M1 with AR price expectations, but for the broader aggregates -- with the exception of the AR price expectations specification -- Chow statistics at change points are insignificant. 
5. United Kingdom. Change points for sterling M3 occur in 1973 Q4, and Chow statistics are significant in most cases. This period was associated with a greater emphasis being placed on controlling sterling M3, following the collapse in velocity that had been associated with rapid monetary growth after Competition and Credit Control in 1971 . It was also associated with the introduction of the Supplementary Special Deposit Scheme ("corset"), which imposed effective ceilings on the ability of banks to finance lending by bidding for interest bearing deposits. The break points for Ml, on the other hand -- with the exception of the AR price expectations specification -- do not give rise to significant Chow statistics.

6. Italy. Significant change points occur for all specifications of the $\overline{M 2}$ and M3 equations in the middle and late 1970s. These may be associated with variability in the forcefulness with which credit ceilings were used in the conduct of monetary policy. Only the M1 specification without price expectations demonstrates consistent stability.

7. Canada. Highly significant change points occur for a11 specifications of the broad money demand equations, mostly around 1980 and 1981. This seems to be associated with financial innovation. Since the end of 1979, chartered banks began to offer deposit accounts with near market interest rates on daily balances. However, with the exception of the RW price expectations specification, no change points are associated with significant Chow statistics in the case of the adjusted MlA aggregate.

\section{E. An overview of the stability results}

The main findings from the above stability tests are summarized in Table 3. Most emphasis was placed on the Chow test applied to the break points identified by the Quandt log-likelihood ratio. In 33 out of 57 cases the estimated equations fail this test. However, at least one specification of money demand passes both the standard Chow test applied to the 1979 break point and that identified by the Quandt ratio, for every country that did not pass the cusum and/or cusum of squares tests. Moreover, none of these preferred specifications are rejected by the homogeneity and time trending regression tests that were applied. It is of some interest to note that with the exception of M3 in the United States and M2 and M3 in Canada, most change points identified by the Quandt ratio seem to have been associated with changes in monetary policy targets and/or instruments, rather than with periods of innovation in financial markets. However, it is also possible that the statistical test employed to identify change points may not be sufficiently refined, particularly if the aggregates concerned have been affected by innovations that have been partially compensating in nature. Strong conclusions on the importance of financial innovations may not be warranted at this point in time. 
Table 3

OVERVIEW OF STABILITY RESULTS

$A=$ Equation with RW price expectations preferred

$B=$ Equation with $A R$ price expectation preferred

$\mathrm{C}=$ Equation with inflation term suppressed preferred

- = No stable equation

\begin{tabular}{llll}
\hline & M1 & M2 & M3 \\
United States & A, B & B & - \\
Japan & A, B, C & - & n.a. \\
Germany & C & B & A, B, C \\
France & - & A, C & A, C \\
United Kingdom & A,C & n.a. & - \\
Italy & C & - & - \\
Canada & B,C & - & - \\
\hline
\end{tabular}

IV. PREFERRED EQUATIONS AND TEST OF THE LAG STRUCTURE

Many of the estimated money demand equations for alternative aggregates and/or specifications of price expectations were rejected on theoretical grounds because unexpected signs on coefficients arose or because long-run elasticities seemed implausible. They were also rejected on statistical grounds when key parameters were insignificantly different from zero at a reasonable level of probability, or when significant autocorrelation was present. Moreover, some specifications which seemed acceptable on theoretical and statistical grounds (summarized in Table 2) were rejected when submitted to a battery of stability tests (compare Tables 2 and 3 ). Nevertheless, one of the above alternative specifications for at least one monetary aggregate proved to be acceptable for each of the major OECD countries. These preferred results are reported in full in Table 4. In some countries the demand for real money balances without an expected inflation term was preferred: Germany M3; France M2; the United Kingdom M1; Italy M1 and Canada M1A. In contrast, the price expectations term improved the explanatory power of the preferred M2 equation for the United States and the Ml equation for Japan. In both cases the AR price expectations formulation was preferred.

One potential problem with all of the results reported above is that the Koyck lag may be unnecessarily restrictive. This structure has frequently been imposed in previous work on money demand and, as suggested in Section II, was also preferred for various practical reasons in the present study. However, to further explore the properties of the preferred equations the Koyck lag was tested against a more general lag structure of the form (9): 


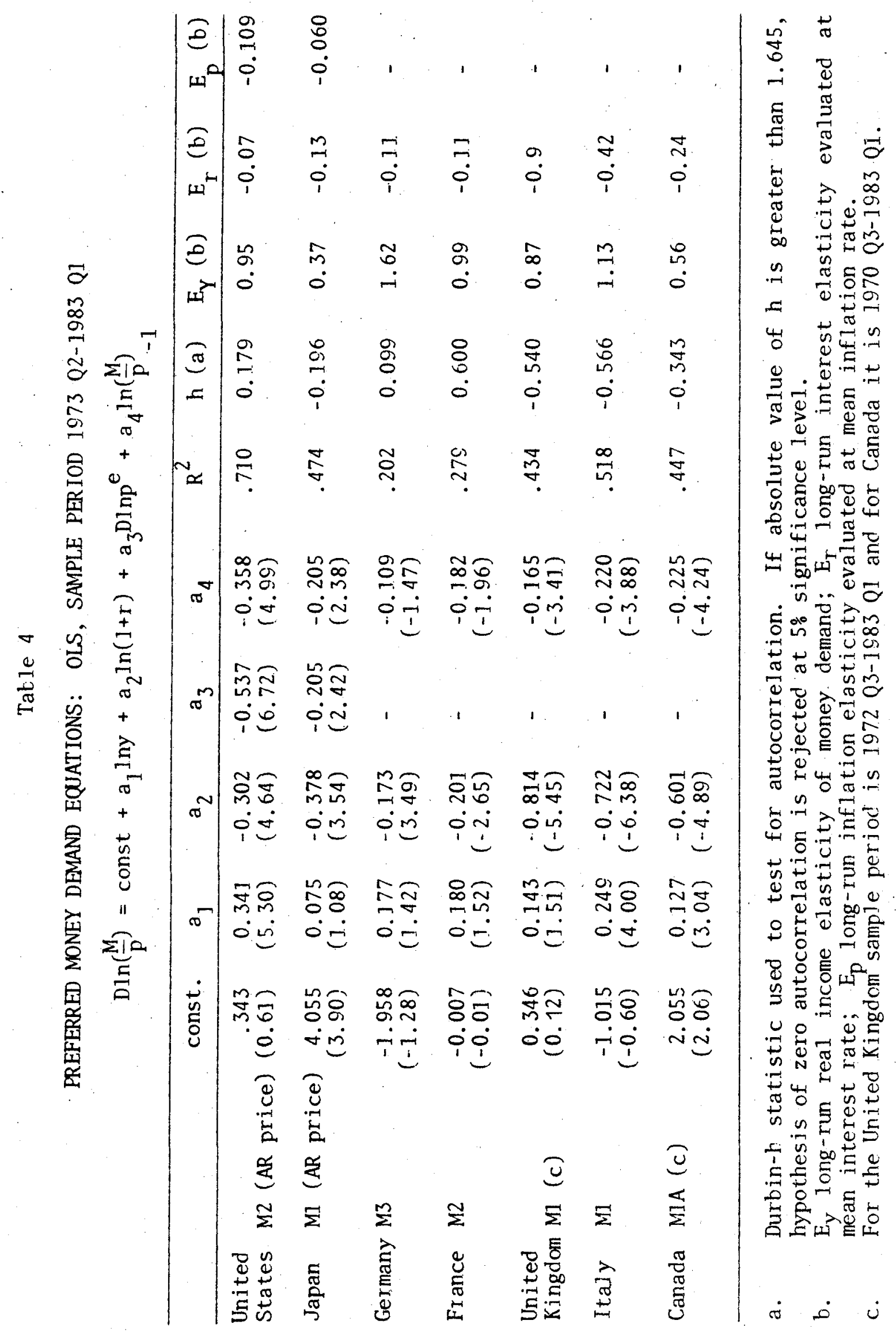




$$
\begin{gathered}
D \ln \frac{M}{p}=\text { Const }+b_{1} \ln y+b_{2} \operatorname{lny}-1+b_{3} \ln (1+r)+\ldots \\
\ldots+b_{4} \operatorname{lng} e^{e}+b_{5} \ln \left(\frac{M}{p}\right)_{-1}
\end{gathered}
$$

The Koyck lag imposed in equation (1) above is nested in equation (5), and imposes the restriction that $b_{2}=0$. This restriction is tested for the preferred equations with a classical likelihood ratio test, the results of which are shown in Table 5. The Koyck restriction is accepted for all countries at the 1 per cent level and only one equation, that for the United Kingdom, is rejected at the 5 per cent level.

Table 5

LIKELIHOOD RATIO TEST OF THE KOYCK RESTRICTION AGAINST A MORE GENERAL ALTERNATIVE LAG STRUCTURE(a)

\begin{tabular}{lccccc}
\hline & Concept & $\begin{array}{c}\text { Price } \\
\text { Expectations }\end{array}$ & $\begin{array}{c}\text { Test } \\
\text { Statistic }\end{array}$ & $\begin{array}{c}\text { Critical } \\
\text { Value 95\% }\end{array}$ & $\begin{array}{c}\text { Critical } \\
\text { Value 99\% }\end{array}$ \\
\hline United States & M2 & AR & 0.404 & 3.84 & 6.63 \\
Japan & M1 & AR & 0.090 & 3.84 & 6.63 \\
Germany & M3 & - & 0.202 & 3.84 & 6.63 \\
France & M2 & - & 0.038 & 3.84 & 6.63 \\
United Kingdom & M1 & - & 5.370 & 3.84 & 6.63 \\
Italy & M1 & - & 0.200 & 3.84 & 6.63 \\
Canada & M1A & - & 1.454 & 3.84 & 6.63 \\
\hline
\end{tabular}

a. The test statistic, which is $x^{2}$ distributed, is $-2\left(L_{r}-L_{u}\right)$, where $\mathrm{L}_{\mathrm{r}}$ is the $\log$ likelihood value of the specification which imposes the Koyck restriction and $\mathrm{L}_{\mathrm{u}}$ is the 1 og-likelihood value of the equation with the more general lag structure. The restriction is rejected if the test statistic exceeds the critical value in the region of the upper tail. 


\section{DYNAMIC SIMULATIONS OF VELOCITY}

To examine the predictive power of the preferred money demand functions, dynamic simulations from 1973.Q1 to 1983.Q1 were carried out. Table 6 presents the mean absolute percentage errors and the root-mean-square percentage errors for forecasts of the levels of velocity resulting from these simulations. The range of the average errors lies between about $1 / 2$ per cent to $23 / 4$ per cent. Chart 1 presents graphs of actual and dynamically simulated velocity. These suggest that simulated level of velocity tracks history reasonably well in all of the countries considered. The relatively low mean errors for simulations with the US M2 function are reflected in a remarkably close relationship between actual and simulated velocity. The rise in the US income velocity of M2 from 1980 Q3 to $1981 \mathrm{Q} 1$, and the steep fall thereafter, is particularly well explained by the arguments of the function. More generally, turning points are predicted reasonably well for all countries.

Table 6

FORECAST ERRORS FOR THE LEVEL OF VELOCITY IMPLIED BY DYNAMIC SIMULATIONS OF DEMAND FOR MONEY EQUATIONS

Sample period 1973 Q2 to 1983 Q1

\begin{tabular}{lcccc}
\hline & Concept & $\begin{array}{c}\text { Price } \\
\text { expectations }\end{array}$ & MAPE (a) & RMSPE (b) \\
\hline United States & M2 & AR & 0.57 & 0.72 \\
Japan & MI & AR & 1.57 & 1.96 \\
Germany & M3 & - & 0.99 & 1.27 \\
France & M2 & - & 0.99 & 1.27 \\
United Kingdom & M1 & - & 2.21 & 2.69 \\
Italy & MI & - & 1.59 & 2.08 \\
Canada & M1A & - & 1.73 & 2.09 \\
\hline
\end{tabular}

a. Mean absolute per cent error.

b. Root-mean-square per cent error. 

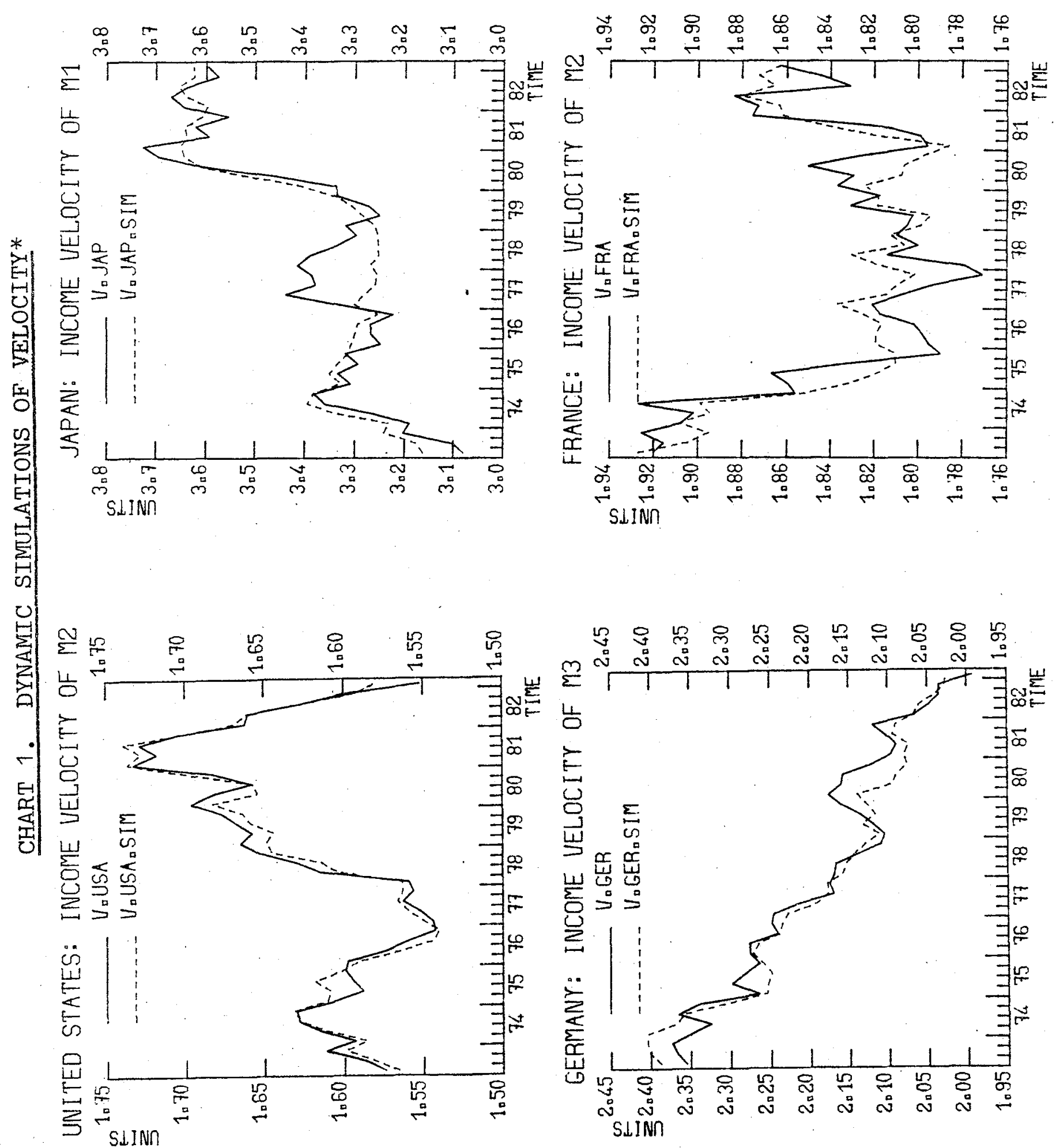


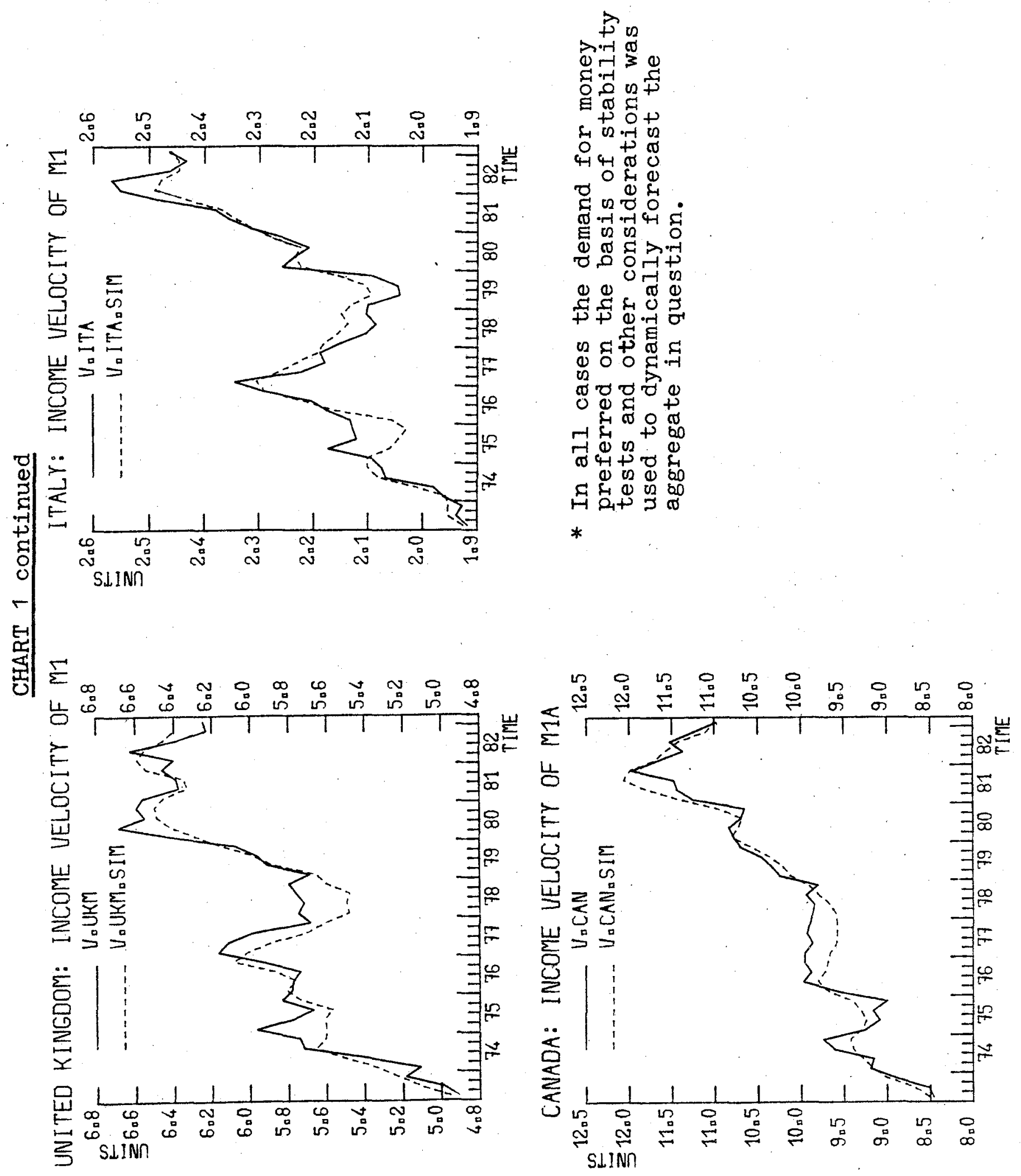




\section{CONCLUDING REMARKS}

Money demand equations for all aggregates, and for alternative assumptions about price expectations, were estimated and subjected to a wide variety of tests concerning their stability and predictive power. An important aim was to examine whether money demand functions are relatively stable, so that recent large swings in velocity could be explained in terms of the arguments of the equations or, particularly in the light of recent financial innovations, whether instability would be a more prevalent finding.

Where instabilities of money demand were clearly identified, they seem often to have been associated with those aggregates which were importantly affected by changes in the techniques of monetary control and/or the use of quantitative controls such as credit ceilings etc., (Ml in the United States, $M 2+C D$ in Japan, sterling $M 3$, and $M 2$ and $M 3$ in Italy). Perhaps somewhat surprising in this context is the stability of the $M 2$ equation in France, since this aggregate has been targeted by the central bank mainly through the use of quantitative controls.

There is evidence to suggest that financial innovations have led to instabilities in the demand for broader aggregates in Canada. However, the adjusted MIA aggregate does not seen to have been so affected. Ml instability could not be closely linked to the recent spate of financial innovations in the United States. The instabilities that arise seem more to be related to the introduction of the new operating procedure in late 1979. However, the instability of M3 demand in the United States is more easily 1 inked to financial deregulation in 1980 and 1981 .

The restriction implied by the Koyck lag structure assumed in estimation was tested against a more general alternative and proved broadly to be acceptable. Inflation expectations, as analysed in this study, do not seem to have important separable explanatory power in the preferred money demand equations, with the exceptions of the United States and Japan. In both of these cases the AR forecast variable seemed to be more appropriate.

In sum, while there is evidence for money demand instability in the case of some aggregates, a reasonably stable equation can be identified for a11 of the major seven OECD countries. These preferred equations provide adequate predictions of the large swings in velocity during the 1970 s and $1980 \mathrm{~s}$. It is also interesting to note that the preferred equation, particularly in the recent past, is often associated with a monetary aggregate which the authorities have chosen (de facto or de jure) to target. M2 is targeted in both the United States and France (10). While central bank money is targeted in Germany, this is normally associated with control over the broad M3 aggregate. MI has become an increasingly important indicator and target variable in the United Kingdom during the 1980s. The adjusted MlA aggregate in Canada is conceptually not far from the $\mathrm{Ml}$ variable which was the object of monetary targets prior to their suspension in 1982 (1I). Only in Japan and Thaly have the authorities paid little attention, in their announced intentions, to the preferred aggregate (in both cases MI) for which a stable demand function was identified. In these latter two countries, however, it may not follow that the relationships would remain stable if the authorities began to focus more on narrow monetary aggregates when formulating their policies. 


\section{NOTES}

1. See for example Poole (1970), Henderson (1979), OECD (1984).

2. See for example OECD (1979) and references therein.

3. In the United States the authorities have downgraded the importance attached to $M I$ in policy formulation, and in Canada monetary targeting has been suspended, because of such concerns.

4. It should be mentioned at the outset that a number of additional variables were also tested. These include long-term interest rates and variables (purchasing power parity and the rate of change of the exchange rate) which were intended to capture the influence of exchange rate expectations. An inflation expectations variable derived from the term structure of interest rates was also tried. In all cases these specifications gave rise to counter-intuitive signs, statistically insignificant parameter estimates, and/or results which were inferior to those obtained for the basic specification discussed above. Since a large number of results are already reported below, results for these alternative specifications have not been included.

5. This corresponds with the introduction of the new operating procedure in the United States, whereby more emphasis was to be placed on non-borrowed reserves as an operating instrument. This was expected to give rise to greater uncertainty and more interest rate variability within the United States and, through international financial linkages, other countries.

6. The technique of recursive regressions involves estimating regressions over a certain time span that is extended one period at a time. Subsequently, the cumulated sums of recursive residuals are computed. They are -- up to a scaling factor -- the errors in the values of each observation of the dependent variable predicted from a regression on al1 the preceeding observations. In other words, the one-step prediction errors are being analysed. The calculations can be done in two directions, forwards and backwards, providing two tests per technique. The cumulative sums (cusums), and cusums of squares of these one-step prediction errors, display under the hypothesis of stability a random movement about the expected mean value. If the regression parameters are constant up to a certain point in time, but differ from these constant values subsequently, the recursive residuals will have a zero expectation up to this period but non-zero expectation afterwards.

7. It should also be kept in mind that the cusum and cusum of squares tests are approximate, and that the latter is particularly biased, tending to reject the null hypothesis more frequently than an exact test would do.

8. For as many observations as possible, depending on degrees of freedom. See Quandt, R.E. (1966). See also R.S. Brown, J. Durbin and J.M. Evans (1975) for a discussion of some of the other tests discussed above. 
9. This specification is an even more general form of the error correction approach proposed by D.F. Hendry, which imposes the restriction $b_{2}=b_{5}-b_{1}$. See D.F. Hendry and T. von Ungern-Sternberg (1981) for an explanation and application of this approach.

10. The robustness of the US M2 equation is in spite of distortions associated with ceilings on deposit interest rates prior to de-regulation.

11. The new MIA aggregate takes account of deposits which include large elements of transactions balances which had been excluded from M1. Apart from a levels adjustment, however, their behaviour over time has been similar.

\section{REFERENCES}

BROWN, R.S., J. Durbin, and J.M. Evans (1979), "Techniques for Testing the Constance of Regression Relationships Over Time", Journal of The Royal Statistical Society, Vo1. B37.

HENDERSON, D.W. (1979), "Financial Policies in Open Economies", American Economic Review, Papers and Proceedings, Vol. 69, No.2.

HENDRY, D.F. and T, von Ungern-Sternberg (1981), "Liquidity and Inflation Effects on Consumers' Expenditure", in Deaton, A. (ed.), Essays in the Theory and Measurement of Consumers Behaviour, Cambridge University Press.

OECD (1979), "Demand for Money in Major OECD Countries", OECD Economic Outlook, Occasional Studies, January.

OECD (1984) forthcoming, "Exchange Rate Management and the Conduct of Monetary Policy, OECD Monetary Studies Series.

POOLE, W. (1970), "Optimal Choice of Monetary Policy Instruments in a Simple Stochastic Macro Mode1", Quarterly Journal of Economics, May.

QUANDT, R.E. (1966), "Tests of the Hypothesis that a Linear Regression System Obeys Two Separate Regimes", Journal of the American Statistical Association, June. 
ANNEX

DETAILED TABLES OF ESTIMATION RESULTS AND STABILITY TESTS

Table

Page

Al AR PRICE EQUATION RESULTS

A2 NARROW MONEY DEMAND M1 RESULTS (RW price expectations)

A4 BROAD MONEY DEMAND M2 RESULTS (RW price expectations) 


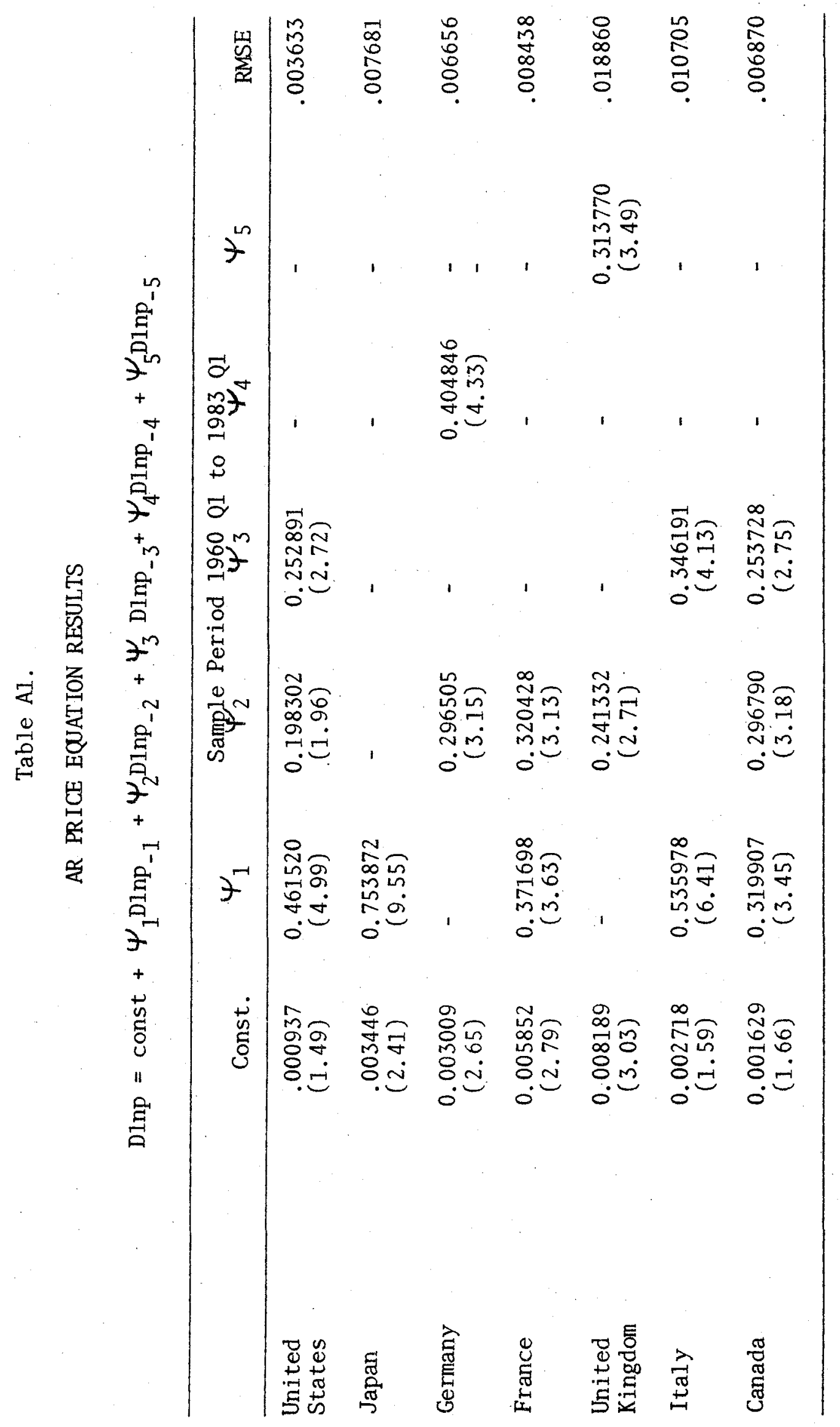




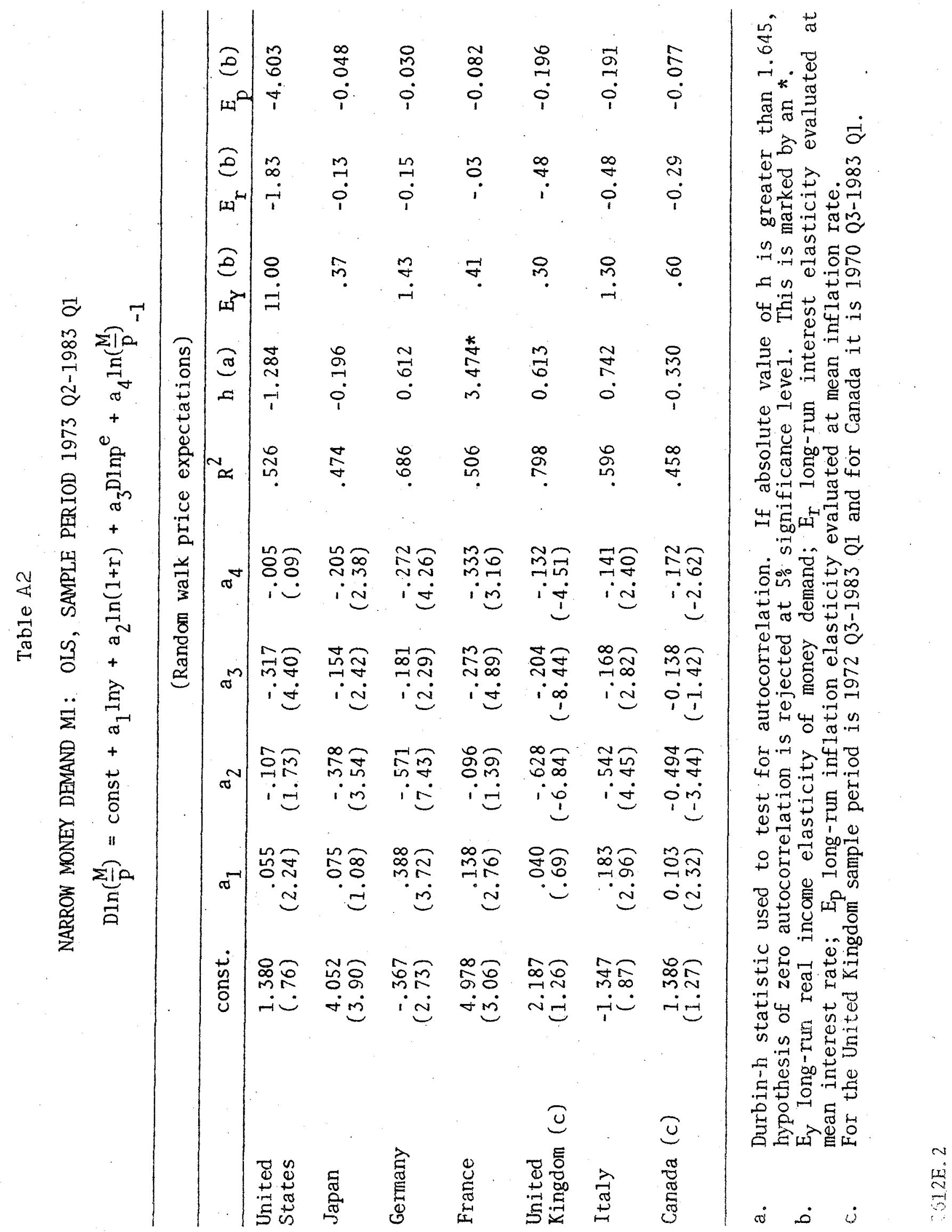




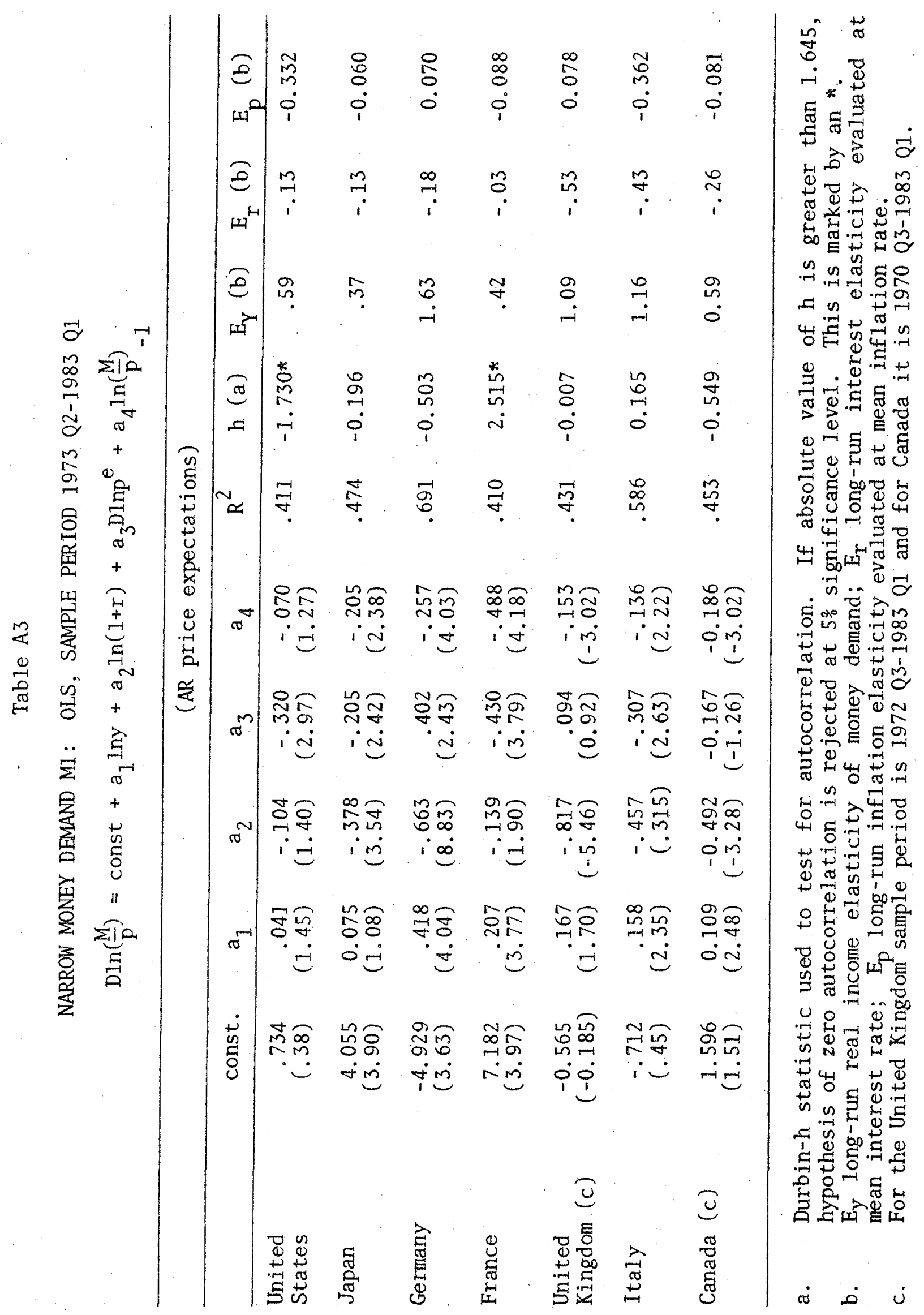




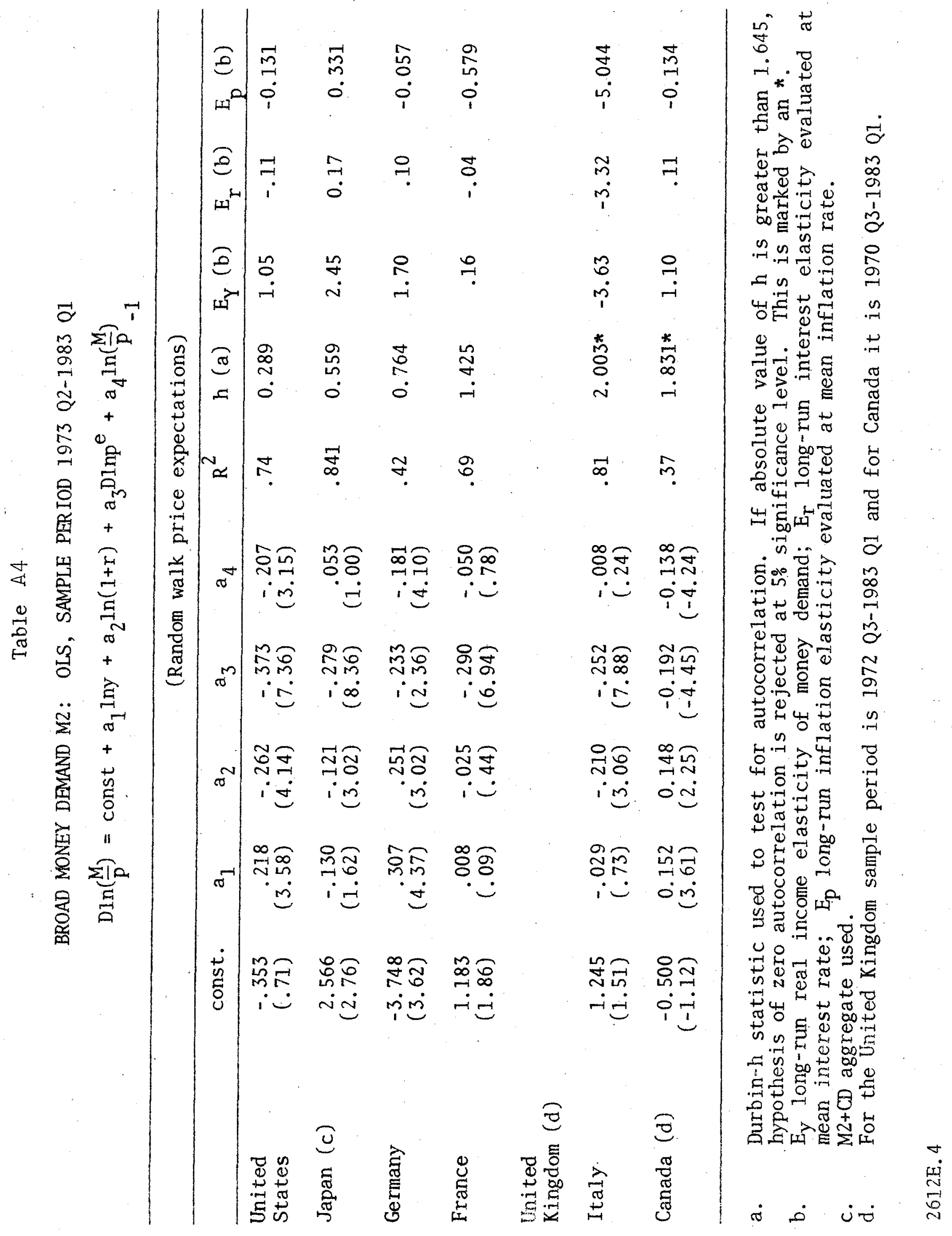




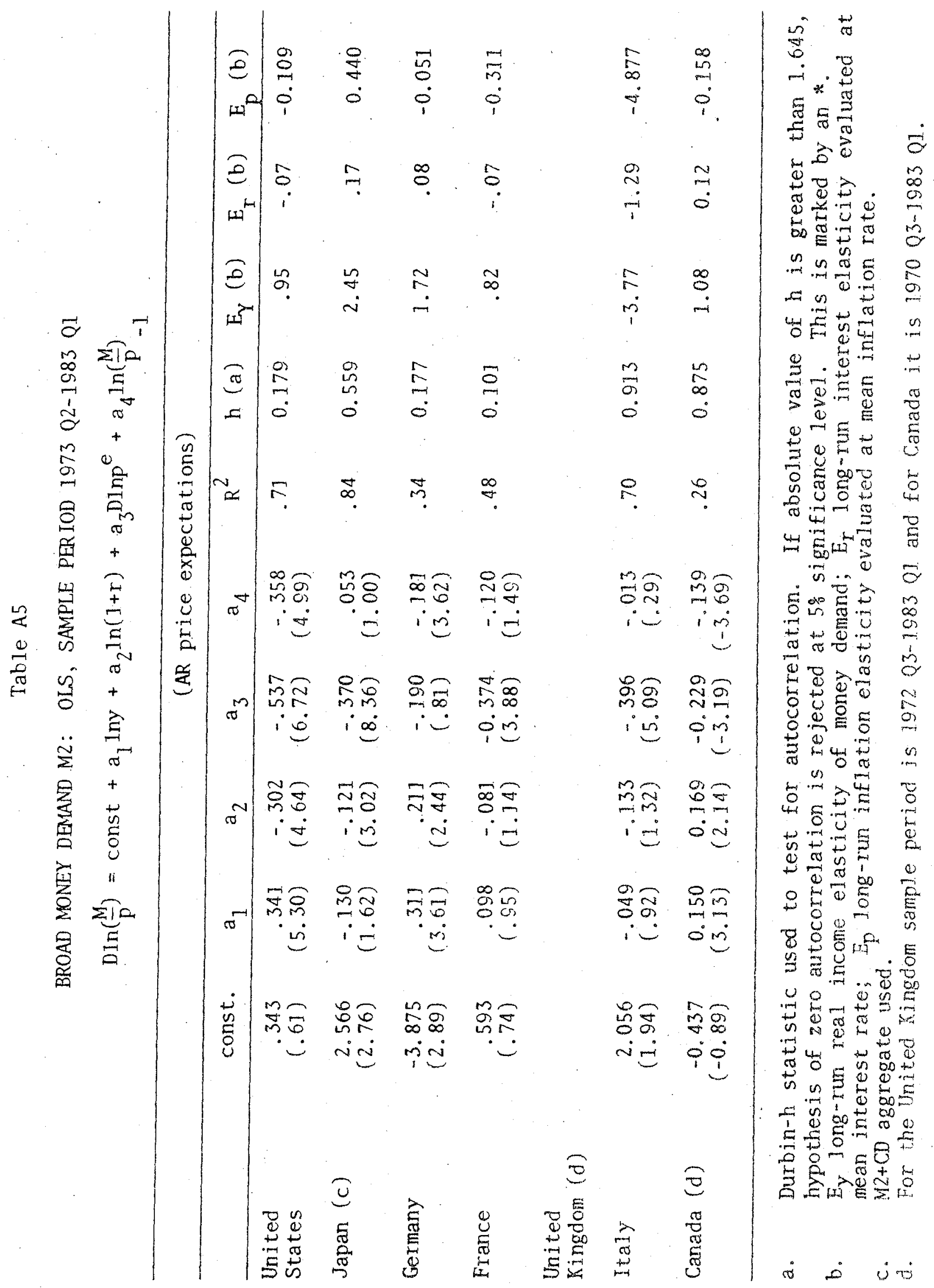




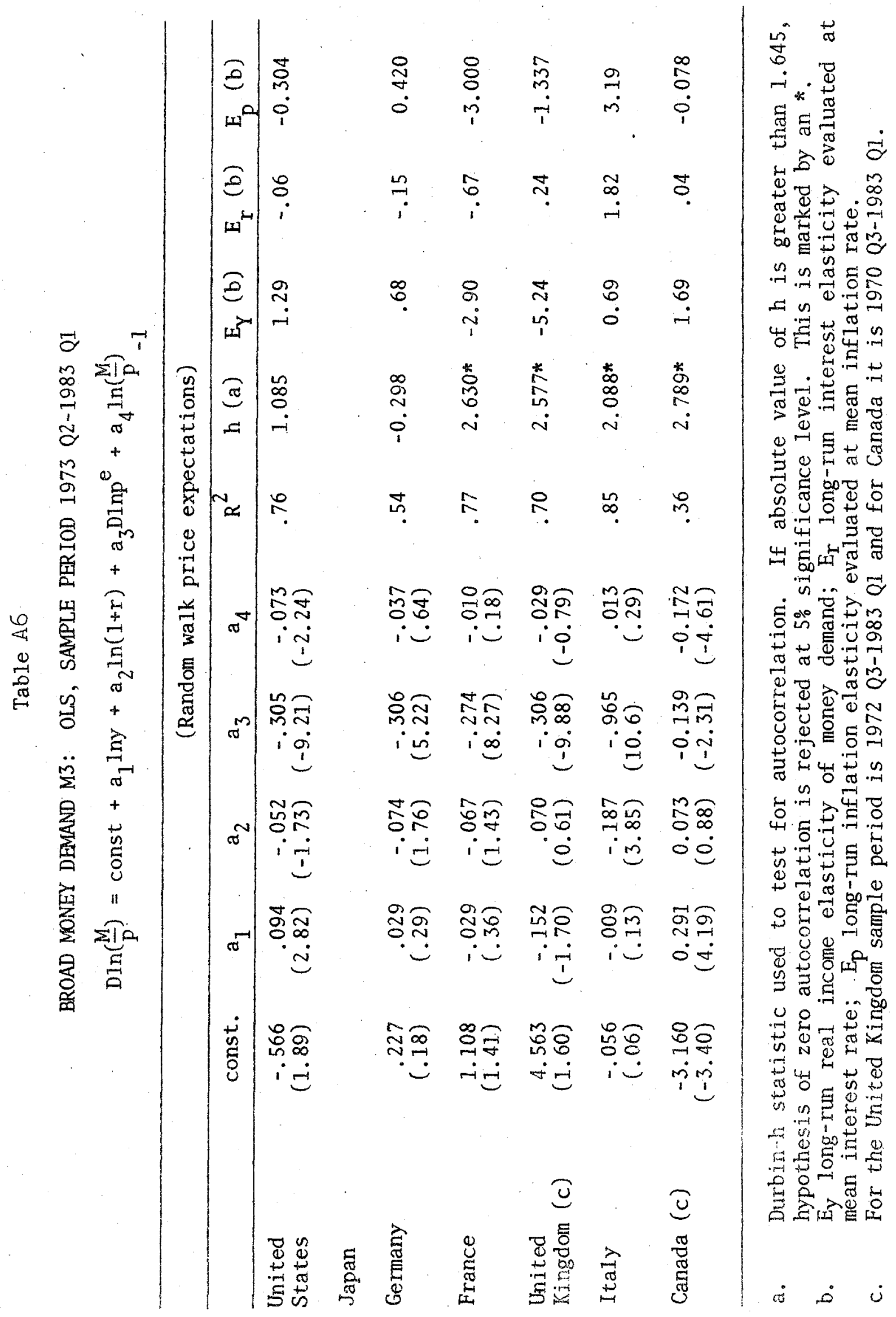




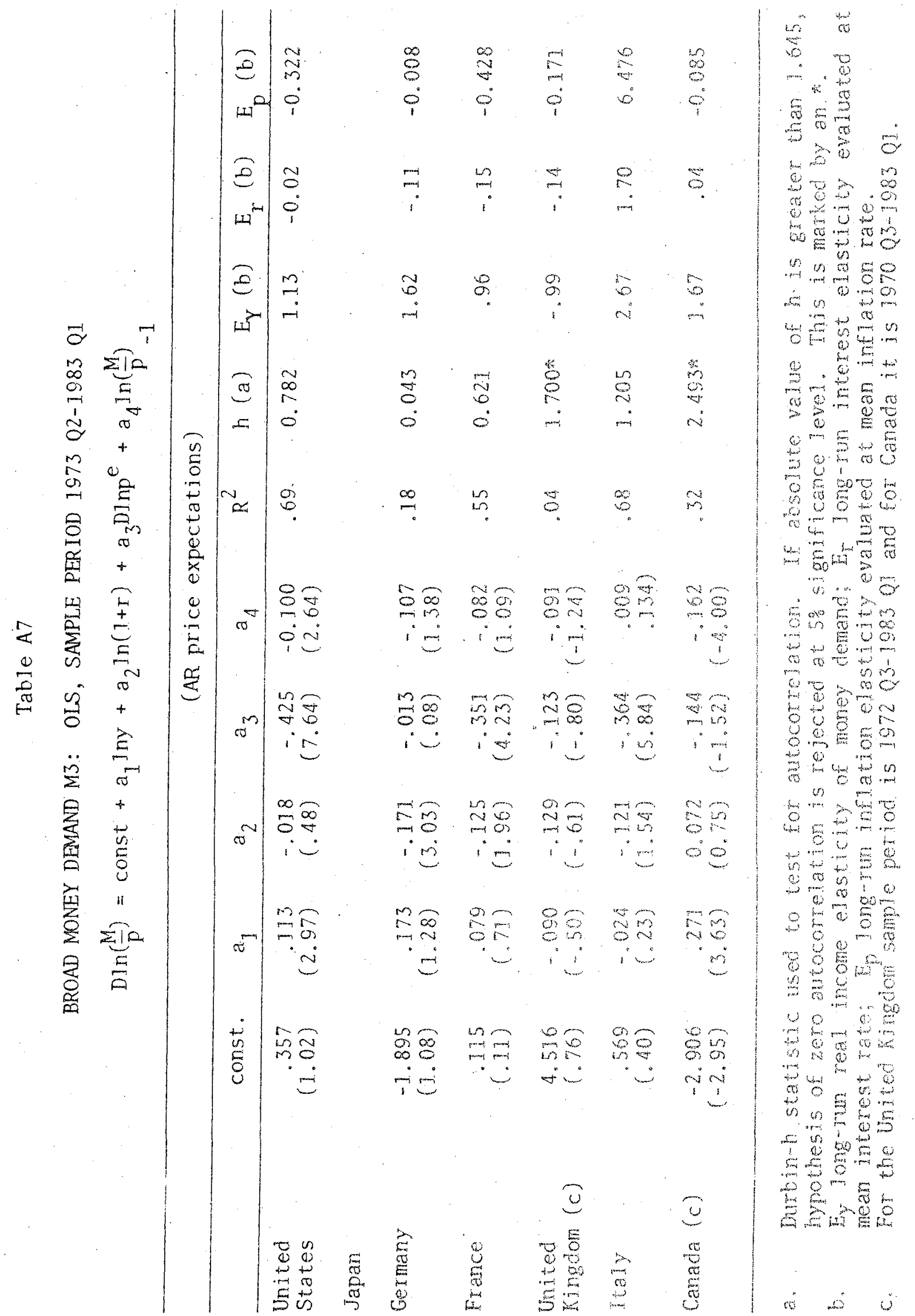




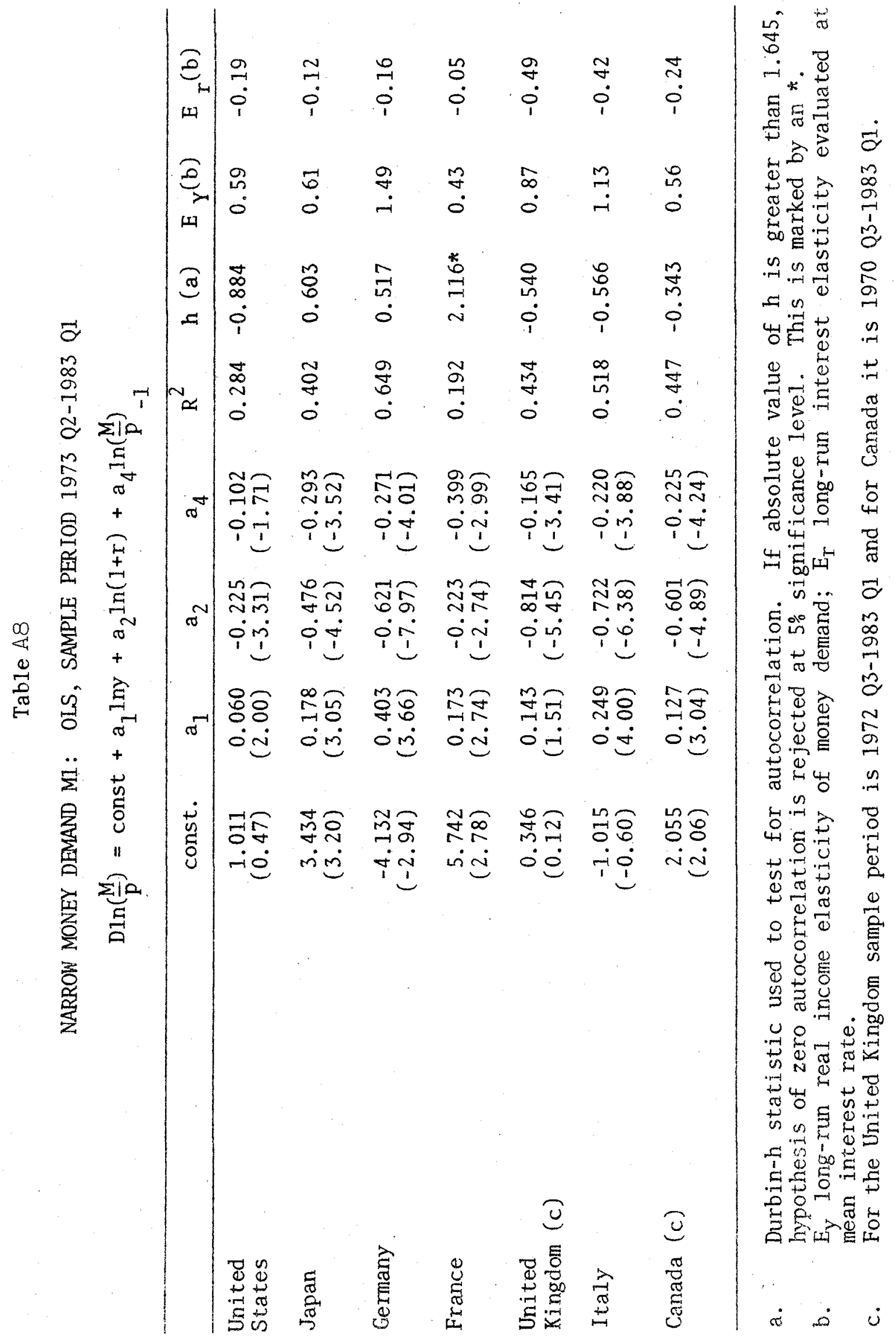




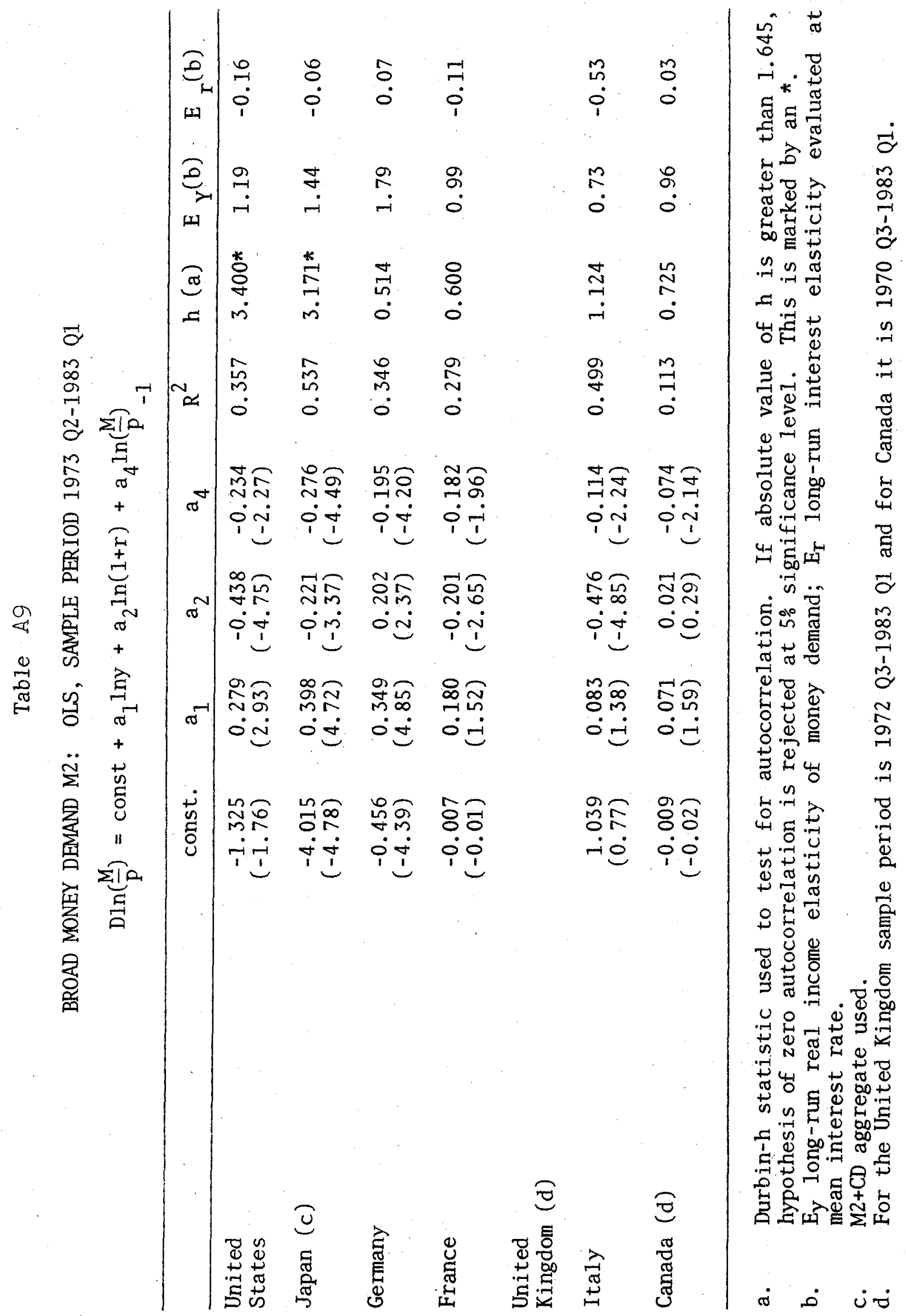




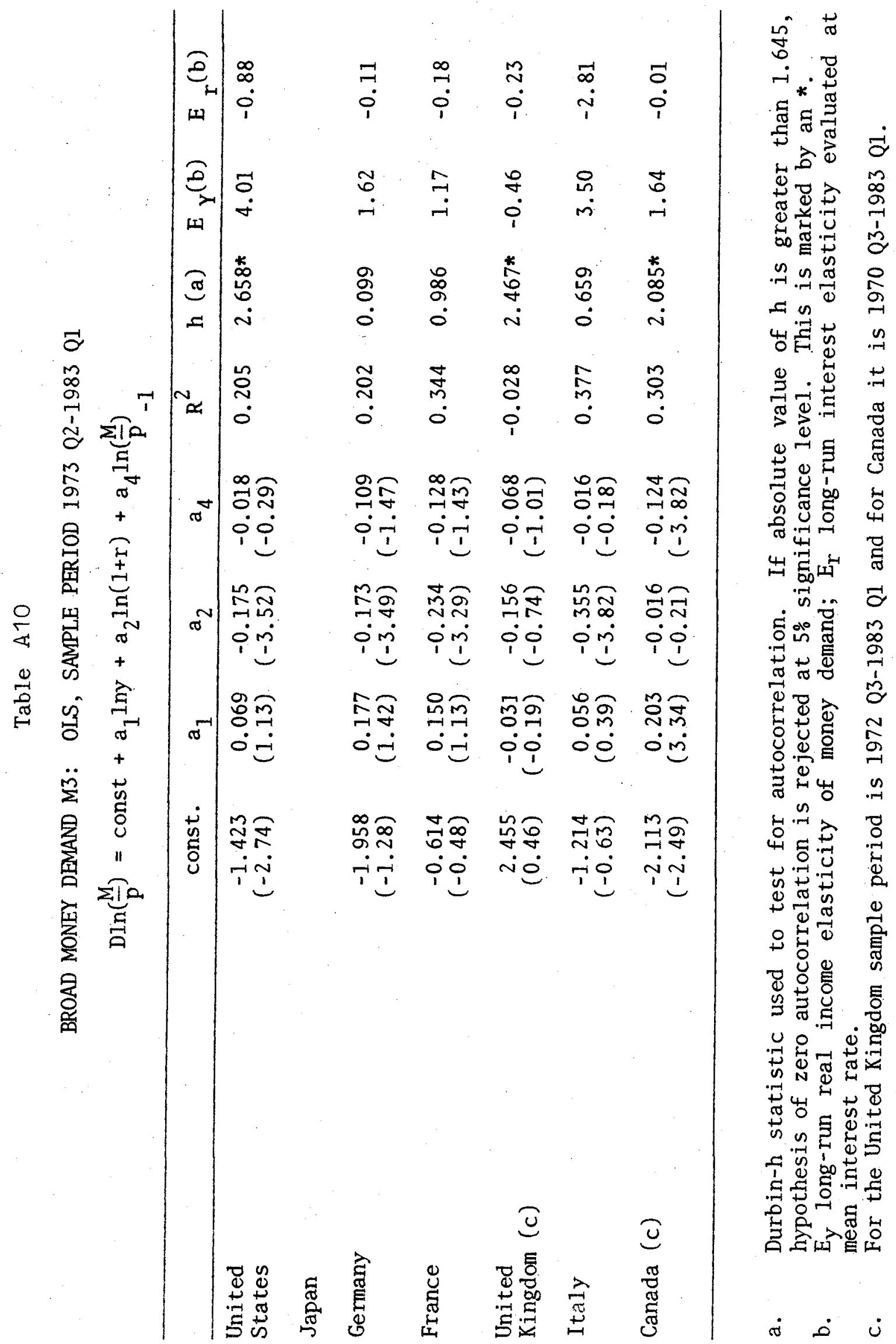




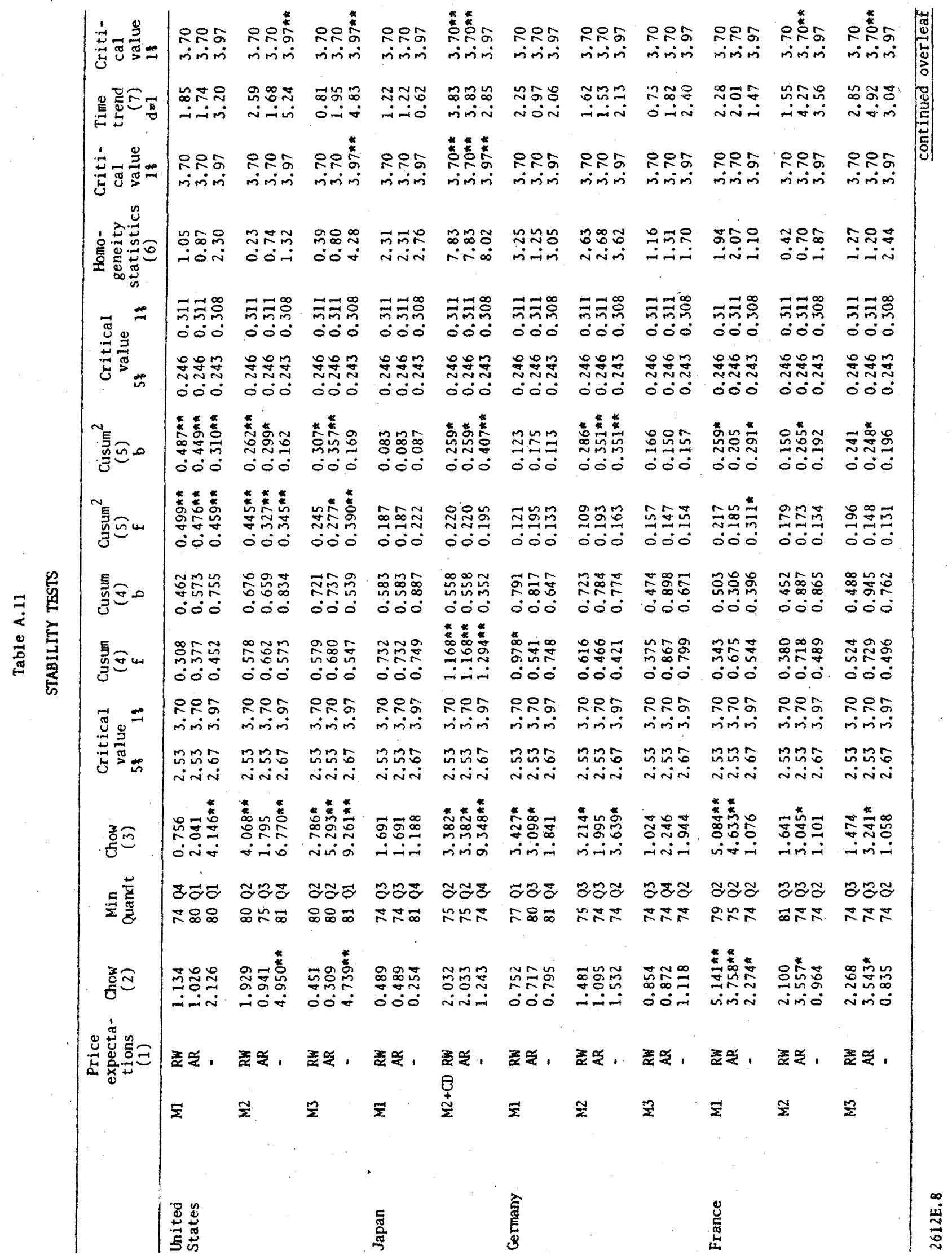




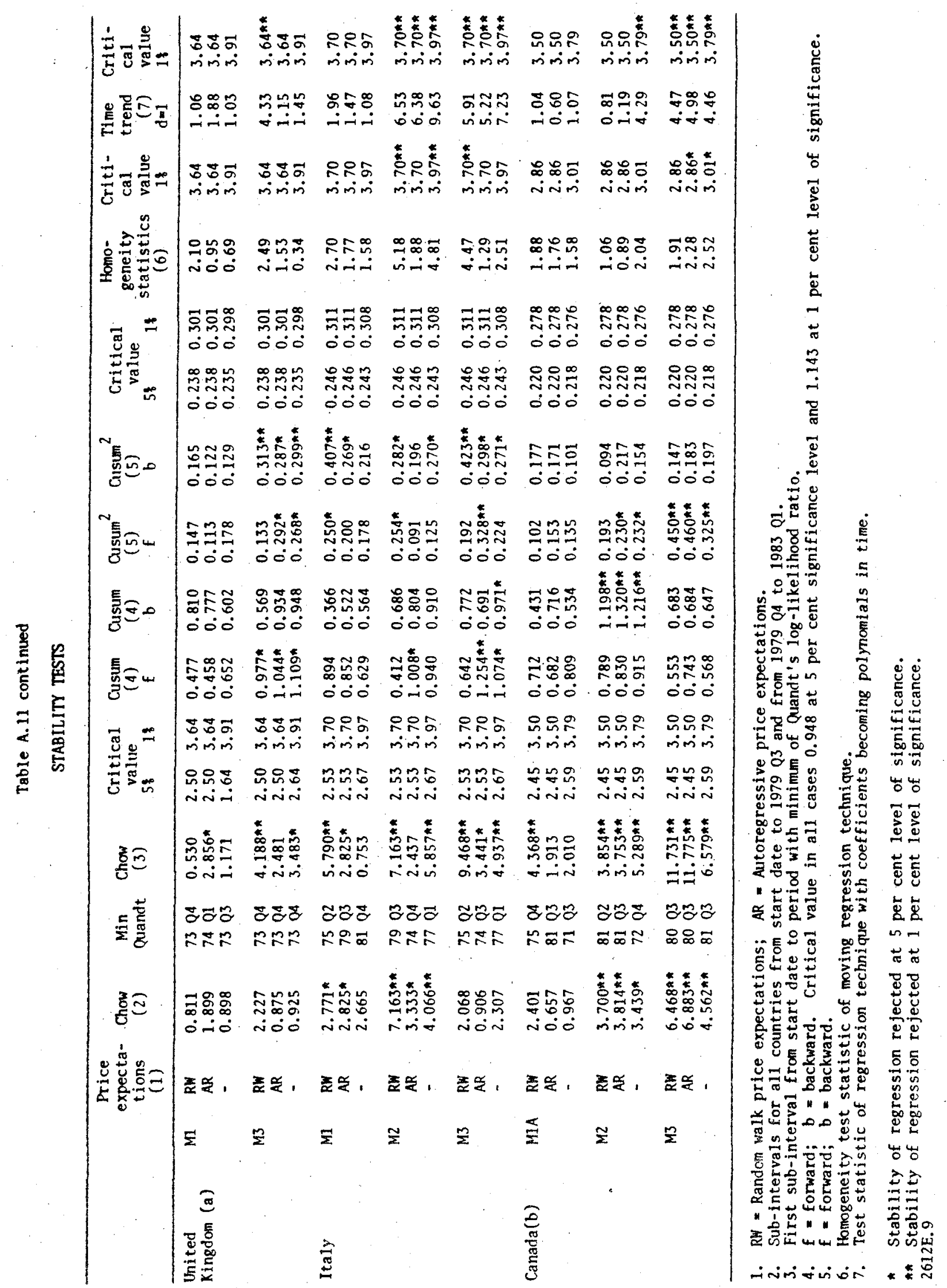

